\title{
Pediatric rheumatology in Africa: thriving amidst challenges
}

\author{
Angela N. Migowa ${ }^{1 *}$ (D), Djohra Hadef ${ }^{2}$, Wafa Hamdi ${ }^{3}$, Oscar Mwizerwa ${ }^{4}$, Madeleine Ngandeu ${ }^{5}$, Yassmin Taha $^{6}$, \\ Faleye Ayodele ${ }^{7}$, Kate Webb $^{8}$ and Christiaan Scott $^{8}$
}

\begin{abstract}
Background: Pediatric Rheumatology is an orphan specialty in Africa which is gradually gaining importance across the continent.

Main body: This commentary discusses the current state of affairs in the sphere of Pediatric Rheumatology across Africa and offers practical strategies to navigate the challenges encountered in research, models of care, education and training. We outline the establishment, opportunities of growth and achievements of the Pediatric Society of the African League Against Rheumatism (PAFLAR).

Conclusion: This commentary lays the foundation for establishment of a formidable framework and development of partnerships for the prosperity of Pediatric Rheumatology in Africa and beyond.
\end{abstract}

Keywords: Pediatric rheumatology, Africa

\section{Background}

Africa is the second most populous continent in the world with an estimated 1.2 billion people and 496 million children $[1,2]$. The pediatric population in Africa is postulated to rise to 661 million by 2030 , becoming the continent with the most children [2]. There are approximately 6-7 million children afflicted worldwide with rheumatic disease and the majority of these, approximately 78\%, live in Asia and Africa [3-5]. Rheumatic diseases often result in pain, disability, poor mental health and increased all-cause mortality [6]. Pediatric Rheumatic Diseases (PRDs) are perceived to be rare in Africa probably due to lack of local expertise and reporting [3-5]. In reality, there are significant numbers of children with rheumatic diseases in Africa who deserve care [3-5]. Acknowledging the burden of pediatric rheumatic diseases across Africa is an important critical step in providing care to these patients [7-15]. As we

\footnotetext{
*Correspondence: angela.migowa@paflar.org; angela.migowa@aku.edu ${ }^{1}$ Aga Khan University Medical College East Africa, Department of Paediatrics and Child Health, 3rd Parklands Avenue, P. O Box 30270, Nairobi, Kenya Full list of author information is available at the end of the article
}

strive to achieve universal healthcare, noncommunicable diseases such as PRDs require attention [16-18]. Developing the pediatric rheumatology workforce is a prerequisite to providing children with rheumatic diseases access to healthcare and good clinical outcomes [19]. Significant strides have been made to promote the discipline of Pediatric rheumatology in Africa as evidenced by the various centers that exist in the 10 of the 54 countries in Africa illustrated in Table 1 and Fig. 1. However much more still needs to be done to establish pediatric rheumatology services across the continent.

\section{The current state of pediatric rheumatology in Africa}

\section{A. Research}

Epidemiological data concerning PRDs among children across Africa is scarce [20]. There are insufficient resources for research [21-23]. There is considerably less industry support in African countries [24, 25]. Studies from Africa are mostly hospital-based case series and may lack applicability to the community [26]. 


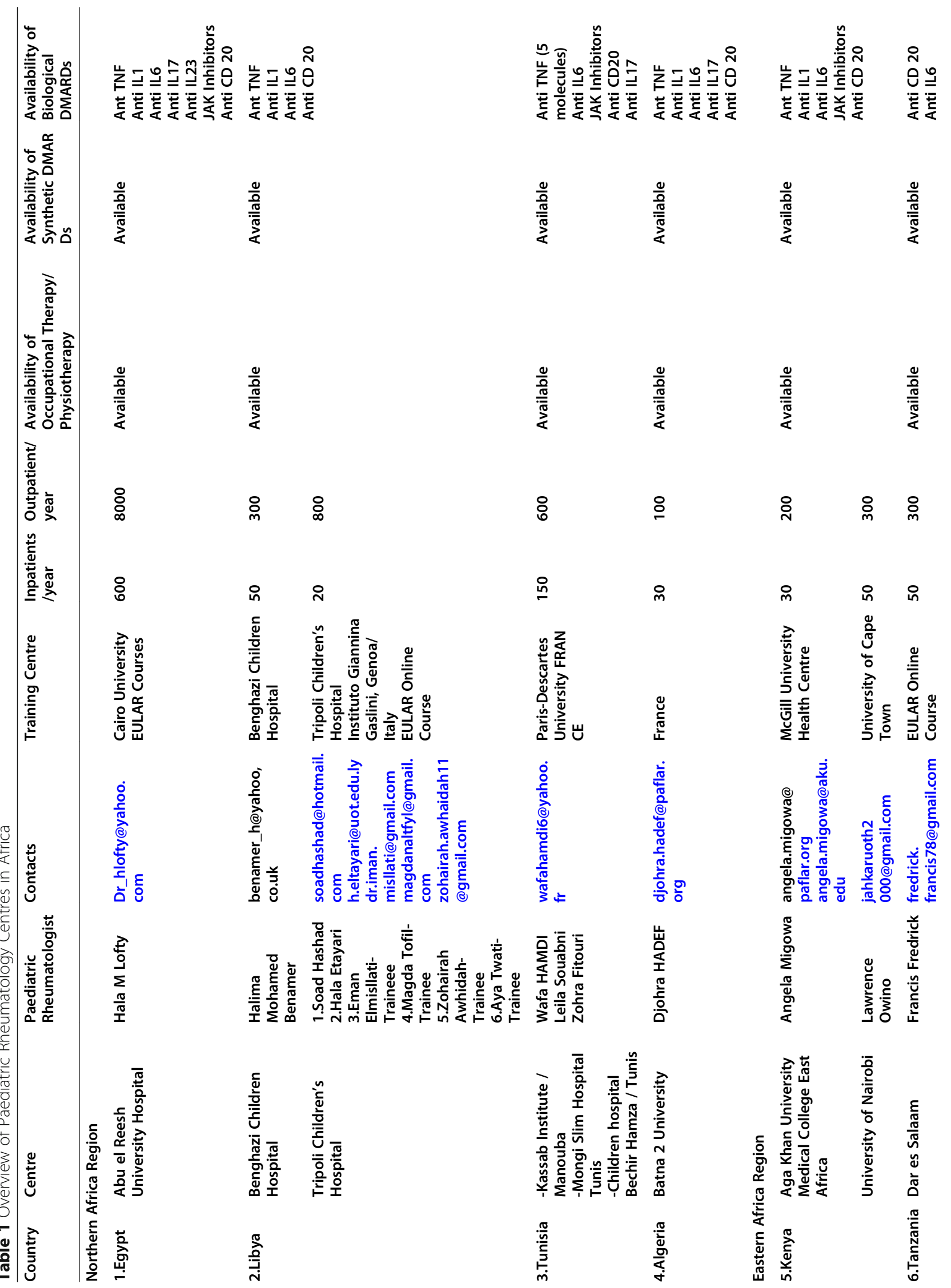




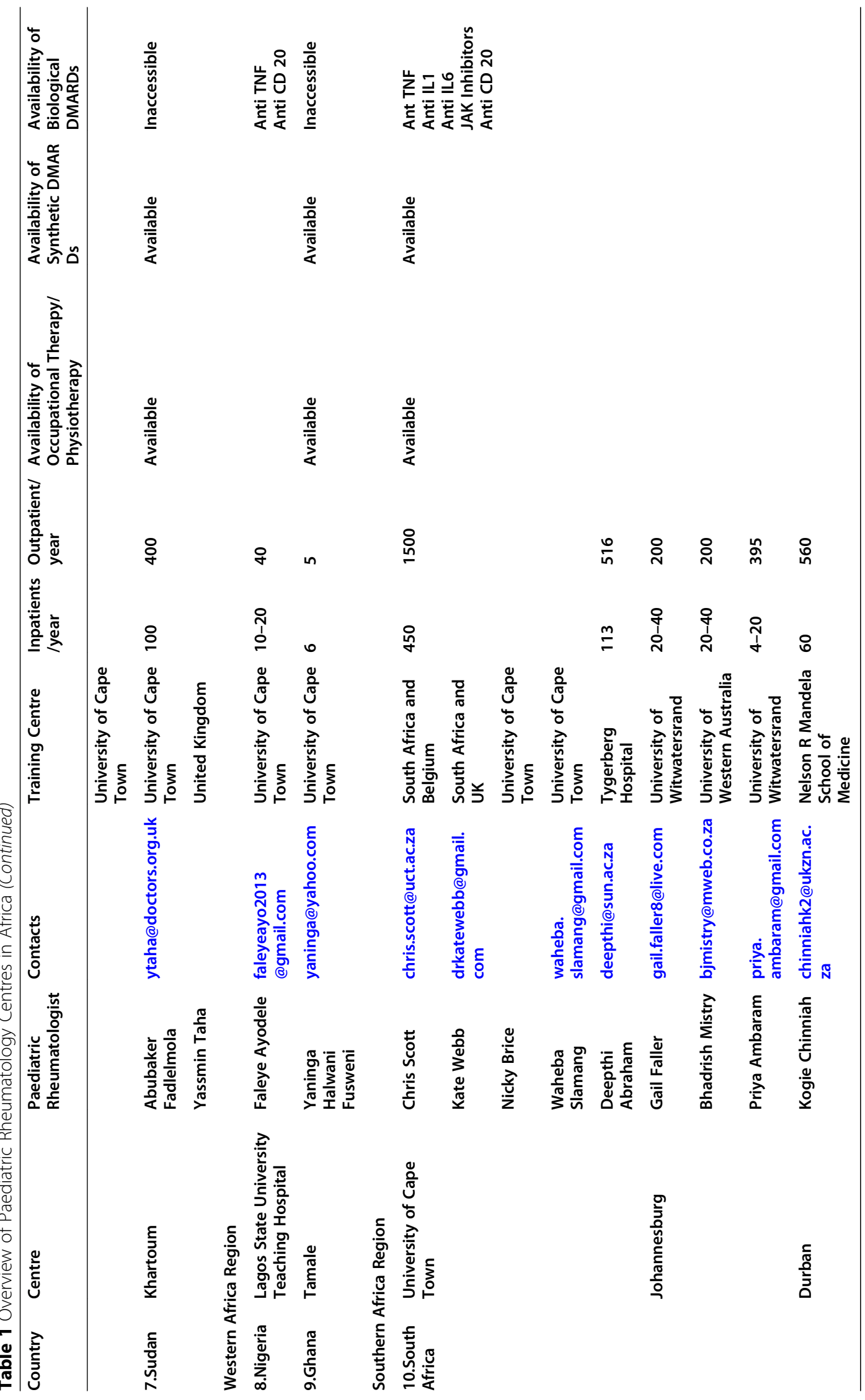




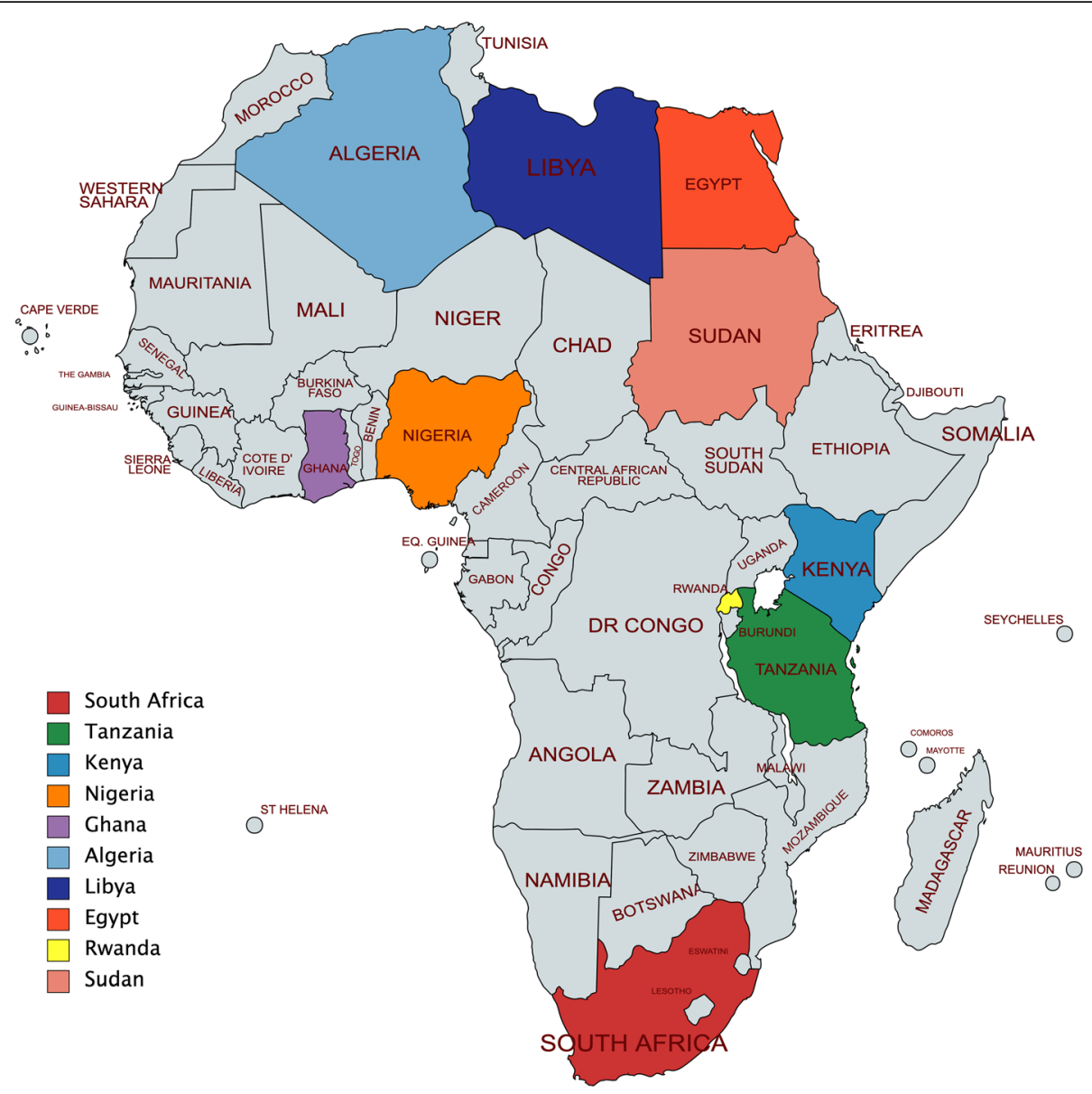

Fig. 1 African Countries with Pediatric Rheumatology Centres

Despite the challenges, there are deliberate efforts to bridge the research gap in pediatric rheumatology across Africa [22-27]. Research has been carried out in the field of lupus and juvenile idiopathic arthritis among other rheumatic diseases [1, 11, 19-27]. It is imperative that we not only describe the disease phenotypes but aim to include our patients in biological research.

In Kenya and South Africa for example, there are nationwide collaborative studies on Multisystem Inflammatory Syndrome in Children (MIS-C) in order to describe the clinico-epidemiological characteristics and outcomes of MIS-C [28]. The African League Against Rheumatism (AFLAR) study on COVID-19 showed the benefits of pulling together both adult and pediatric rheumatologists to work on a common research agenda for the continent [29]. This is an indicator of the potential for more research collaborations among member countries of the AFLAR involving both pediatric and adult rheumatologists [29].

One of the key pillars in PAFLAR's strategic plan is to build research by promoting collaborative efforts, establishment of registries, an ethical review board and a journal to showcase research from Africa. This shall be spearheaded by the existing PAFLAR Scientific Committee.

\section{B. Models of Care Telemedicine}

There is a paucity of medical personnel across Africa with only 2.7 physicians per 10,000 people in Africa compared to 5.9 in South East Asia, 12.7 in the eastern Mediterranean, 15.5 in the Western Pacific, 21.5 in the Americas, and 32.1 in the European region [30]. Retention of trained specialists poses a challenge in Africa due to a lack of supportive frameworks and 'brain drain' [31]. This is challenging particularly when health systems are strained. Telemedicine offers a plausible solution [32]. Recently, there has been increased access to and reliance on remote meeting systems [33]. Tele-consults through platforms such as zoom can be used to enhance multidisciplinary care for patients. Pediatric rheumatology teams in Nigeria and Kenya for example organize zoom meetings on a need to need basis to discuss and deliberate on patients they mutually have in common in a 
multi-disciplinary approach. Further research is required to explore how best to utilize telemedicine to promote pediatric rheumatology in Africa. In solidarity with global partners, researchers from Africa are participating in the validation of the virtual pediatric gait, arms, leg, spine (PGALS) screening examination as part of a global telemedicine initiative [33]. More research is needed to explore the feasibility of telemedicine for pediatric rheumatology in Africa.

\section{Education and Training I) PAFLAR Webinars}

Since its establishment on September 7th, 2019, the Pediatric Society of the African League Against Rheumatism (PAFLAR) embarked on a series of webinars from the 5 regions of Africa i.e. northern, eastern, southern, central and western regions to help bridge the gap in pediatric rheumatology education. This has helped bring the pediatric rheumatology family in Africa much closer allowing exchange of knowledge where distance has been bridged by digital technology. This also serves as a platform to begin academic mentorship of pediatric trainees who log onto the webinars. In order to expand its reach, PAFLAR shall be collaborating with the Juvenile Inflammatory Rheumatism (JIR) winter school in Switzerland through facilitation of an ILAR grant to offer virtual conferences and webinars to members of both PAFLAR and JIR. The goal is to offer a blended learning experience by combining our PAFLAR webinars and the JIR rheumatology courses through fee subsidies to enrich the learning experience of pediatric rheumatologists and all other healthcare workers who care for pediatric rheumatology patients in the African continent while offering them an opportunity to showcase their clinical experience and expertise with the global rheumatology community.

\section{II) Pediatric Rheumatology Training}

There have been various initiatives to help bridge the gap in the pediatric rheumatology workforce [34-37]. This includes the UWEZO project, a collaboration between Kenyan, United Kingdom (UK) and Swedish rheumatologists who trained an estimated 500 physicians and health workers at 11 sites across Kenya [38]. The International League of Associations for Rheumatology (ILAR) supported onsite training in Zambia for 2 years under the EPAREP project (Enhancement of Pediatric and Adult Rheumatology Education and Practice) [39].

In early 2009, the International League of Associations for Rheumatology (ILAR) funded a program known as the "East Africa Initiative" in order to unite the international rheumatology community to promote rheumatology services in an area that carries $25 \%$ of the world's disease burden but has only $2 \%$ of the world's human resources for health [40]. Consequently, training for the only 2 pediatric rheumatologists in East and Central Africa, who are based in Kenya, was supported by rheumatology units in the United Kingdom (UK,) Canada and South Africa. Collaborations have spurred the growth of pediatric rheumatology in Africa through foundations such as "Rheumatology for All" with outreach activities in Ethiopia and Rwanda (https://rheumatologyforall.org).

Developing hybrid programs of local and international training, as occurs in Kuwait and Saudi Arabia, may be more feasible and sustainable [14, 15]. The Pediatric Rheumatology European Society (PReS) and other bodies may look to set up "sister hospital initiatives" where "areas of need" partner with well-resourced hospitals to provide education and clinical support. A similar initiative was successfully undertaken as part of the southern hemisphere educational partnership for pediatric arthritis and rheumatological diseases (SHEPPARD) program between Argentina and South Africa [34]. These kinds of activities happen informally all the time, but a centralized or regional system would enable people to access them more easily.

\section{Conclusion}

This is a long journey which has already started and is gaining momentum. Initiatives such as the creation of a Pediatric Society of the African League Against Rheumatism (PAFLAR), the creation of Global Task Force for Musculoskeletal Health and PReS (Pediatric Rheumatology European Society) initiatives indicate that a core group of rheumatology health care providers and indeed the global community, have recognized that reaching out to the millions of children who live with rheumatic diseases in areas or situations where appropriate care is unavailable or inaccessible is a moral imperative.

\section{Acknowledgements}

We thank Hala M Lofty, Halima Mohamed Benamer, Soad Hashad, Hala Etayari, Lawrence Owino, Yaninga Halwani Fusweni and Gail Faller for sharing an overview of Pediatric Rheumatology in their respective countries.

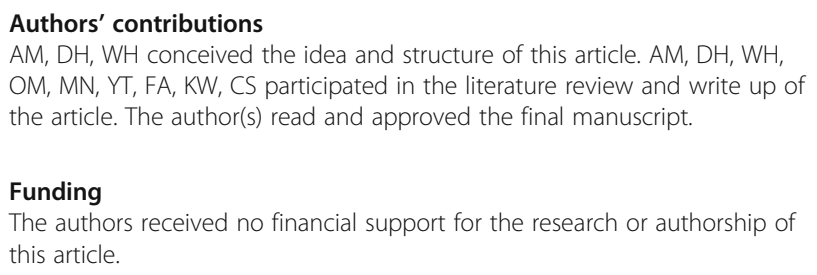

Availability of data and materials Not Applicable.

\section{Declarations}

Ethics approval and consent to participate Ethical approval was not deemed appropriate for this study. Consent from patients is not applicable in this article. 


\section{Consent for publication}

All authors give consent for publication.

\section{Competing interests}

The authors declare that they have no competing interests. The authors have no financial relationships relevant to this article to disclose.

\begin{abstract}
Author details
${ }^{1}$ Aga Khan University Medical College East Africa, Department of Paediatrics and Child Health, 3rd Parklands Avenue, P. O Box 30270, Nairobi, Kenya. ${ }^{2}$ Batna 2 University, Faculty of Medicine, 05000 Ezzohor city, Batna, Algeria. ${ }^{3}$ University of Tunis El Manar, Campus Universitaire Farhat Hached B.P. $n^{\circ} 94$ Rommana Tunis, 1068 Tunis, Tunisia. ${ }^{4}$ University of Rwanda, KG 11 Ave, Kigali, Rwanda. ${ }^{5}$ University of Yaoundé, Boîte Postale 337, Yaoundé, Centre Region, Cameroon. ${ }^{6}$ Ahmed Gasim Children's Hospital Khartoum, Sudan Bahri Street, Downtown, Tuti Island, Bahri, Khartoum State, Sudan. 'Lagos State University Teaching Hospital, Nigeria 1- 5 Oba Akinjobi Way, Street, Ikeja, Lagos, Nigeria. ${ }^{8}$ University of Cape Town, South Africa Rondebosch, Cape Town 7700, South Africa.
\end{abstract}

Received: 24 December 2020 Accepted: 16 April 2021 Published online: 07 May 2021

\section{References}

1. Mody GM. Rheumatology in Africa-challenges and opportunities. Arthritis Res Ther. 2017:19(1):49. https://doi.org/10.1186/s13075-017-1259-3.

2. Fund UNICEF. The State of the World's Children [Available from: https://data t.unicef.org/resources/children-in-africa-child-survival-brochure/.

3. Dave M, Rankin J, Pearce M, Foster HE. Global prevalence estimates of three chronic musculoskeletal conditions: club foot, juvenile idiopathic arthritis and juvenile systemic lupus erythematosus. PediatrRheumatol Online J. 2020;18(1):49.

4. Foster HE, Scott C, Tiderius CJ, Dobbs MB. The paediatric global musculoskeletal task force - 'towards better MSK health for all'. Pediatr Rheumatol Online J. 2020;18(1):60. https://doi.org/10.1186/s12969-020-00451-8.

5. Foster HE, Scott C, Tiderius CJ, Dobbs MB. Members of the Paediatric global musculoskeletal task F. improving musculoskeletal health for children and young people - A 'call to action'. Best Pract Res Clin Rheumatol. 2020;101566.

6. Tyrovolas S, Moneta V, Gine Vazquez I, Koyanagi A, Abduljabbar AS, Haro JM. Mental Disorders, Musculoskeletal Disorders and Income-Driven Patterns: Evidence from the Global Burden of Disease Study 2017. J Clin Med. 2020;9:7.

7. Chipeta J, Njobvu P, Wa-Somwe S, Chintu C, McGill PE, Bucala R. Clinical patterns of juvenile idiopathic arthritis in Zambia. Pediatr Rheumatol Online J. 2013:11(1):33. https://doi.org/10.1186/1546-0096-11-33.

8. Olowu WA, Adelusola KA, Senbanjo IO. Clinicopathology of childhood-onset renal systemic lupus erythematosus. Nephrology (Carlton). 2007;12(4):36470. https://doi.org/10.1111/j.1440-1797.2007.00812.x.

9. Furia FF, Godfrey E, Mwamanenge N, Swai P. Spectrum of paediatric rheumatic disorders at a tertiary hospital in Tanzania. Pediatr Rheumatol. 2020;18(1):30. https://doi.org/10.1186/s12969-020-0418-2.

10. Mabiala Babela JR, Ollandzobo Ikobo LC, Nika RE, Moyen G. Study of 11 new cases of Kawasaki disease Congolese. Bull Soc Pathol Exot. 2015;108(4):2504. https://doi.org/10.1007/s13149-015-0445-2.

11. Atijosan O, Simms V, Kuper H, Rischewski D, Lavy C. The orthopaedic needs of children in Rwanda: results from a national survey and orthopaedic service implications. J Pediatr Orthop. 2009;29(8):948-51. https://doi.org/10.1 097/BPO.0b013e3181c18962.

12. Adebajo A, Gabriel SE. Addressing musculoskeletal health inequity in Africa. Arthritis Care Res. 2010:62(4):439-41. https://doi.org/10.1002/acr.20032.

13. Oyoo GO, Mody GM. Report on the fifth African league against rheumatism congress in Nairobi, Kenya. Clin Rheumatol. 2007;26(7):1033-5. https://doi. org/10.1007/s10067-007-0620-3.

14. Genga EK, Moots RJ, Oyoo OG, Otieno FO. Building a rheumatology team for East Africa: a call for action! Rheumatology (Oxford). 2017;56(9):1441-2. https://doi.org/10.1093/rheumatology/kew432

15. Genga EK, Oyoo O, Espinoza LR, Adebajo A. Africa journal of rheumatology: enhancing the visibility of rheumatology in Africa. Clin Rheumatol. 2017: 36(10):2167-8. https://doi.org/10.1007/s10067-017-3761-z.

16. Henrickson M. Policy challenges for the pediatric rheumatology workforce: part II. Health care system delivery and workforce supply. Pediatr Rheumatol Online J. 2011;9:24.
17. Henrickson M. Policy challenges for the pediatric rheumatology workforce: Part III. the international situation. PediatrRheumatol Online J. 2011:9:26.

18. Henrickson M. Policy challenges for the pediatric rheumatology workforce: part I. Education and economics. PediatrRheumatol Online J. 2011:9:23.

19. Scott C, Webb K. Paediatric rheumatology in sub-Saharan Africa. Rheumatology (Oxford). 2014;53(8):1357-8. https://doi.org/10.1093/rheumatology/ket430.

20. Adebajo A, McGill P, Tikly M. Tropical rheumatology--a global issue. Rheumatology (Oxford). 2009;48(6):599-601. https://doi.org/10.1093/rheuma tology/kep063.

21. Mody GM. AFLAR and SARAA 2013 congress--a watershed event for rheumatology in Africa. Clin Rheumatol. 2013;32(7):925-8. https://doi.org/1 0.1007/s10067-013-2296-1.

22. Migowa A, Colmegna I, Hitchon C, Were E, Ng'ang'a E, Ngwiri T, et al. The spectrum of rheumatic in-patient diagnoses at a pediatric hospital in Kenya. PediatrRheumatol Online J. 2017;15(1):4.

23. Adebajo A, Windsor $\mathrm{K}$, Hassell A, Dacre J. Undergraduate education in rheumatology. Rheumatology (Oxford). 2005;44(9):1202-3; author reply 3. https://doi.org/10.1093/rheumatology/keh677.

24. Adebajo AO. Rheumatology in the third world. Ann Rheum Dis. 1990;49(10): 813-6. https://doi.org/10.1136/ard.49.10.813.

25. Adebajo AO. Rheumatology and Africa. Trop Dr. 1992;22(2):86.

26. Adebajo AO, Hazleman BL. Tropical rheumatology--time for action. World Health Forum. 1993;14(3):293.

27. Scuccimarri R, Broten L, Migowa A, Ngwiri T, Wachira J, Bernatsky S, et al. Frequency and spectrum of outpatient musculoskeletal diagnoses at a pediatric hospital in Kenya. Clin Rheumatol. 2019;38(4):1195-200. https://doi. org/10.1007/s10067-018-4376-8.

28. Webb K, Abraham DR, Faleye A, McCulloch M, Rabie H, Scott C. Multisystem inflammatory syndrome in children in South Africa. Lancet Child Adolesc Health. 2020;4(10):e38. https://doi.org/10.1016/S2352-4642(20)30272-8.

29. Akintayo RO, Akpabio A, Kalla A, Dey D, Migowa A, Olaosebikan H, et al. COVID-19 and the practice of rheumatology in Africa: big changes to services from the shockwave of a pandemic. Ann Rheum Dis. 2020:annrheumdis-2020218273. https://doi.org/10.1136/annrheumdis-2020-218273.

30. Organisation WH. World Health Statistics 20152015 [Available from: http://a pps.who.int/.

31. Anton JLM, Cuadros EN. Paediatric rheumatology:where we are coming from and where we are going. Ann Pediatr (Barc). 2020;92(3):3.

32. Organisation WH. Telehealth: World Health Organisation; 2016 [Available from: https://www.who.int/gho/goe/telehealth/en/.

33. Shenoi S, Hayward K, Curran ML, Kessler E, Mehta JJ, Riebschleger MP, et al. Telemedicine in pediatric rheumatology: this is the time for the community to embrace a new way of clinical practice. Pediatr Rheumatol. 2020;18:85. https://doi.org/10.1186/s12969-020-00476-z.

34. Russo RA, Katsicas MM, Webb K, Scott C. Southern hemisphere educational partnership for pediatric arthritis and rheumatological diseases (Sheppard): pediatric rheumatology without borders. Pediatric Rheumatology. 2013;11(Suppl 2):O30.

35. Chang $\mathrm{H}$. Evaluation framework for telemedicine using the logical framework approach and a fishbone diagram. Health Inform Res. 2015;21(4): 230-8. https://doi.org/10.4258/hir.2015.21.4.230.

36. Hwang D, Chang JW, Benjafield AV, Crocker ME, Kelly C, Becker KA, et al. Effect of telemedicine education and Telemonitoring on continuous positive airway pressure adherence. The Tele-OSA randomized trial. Am J Respir Crit Care Med. 2018;197(1):117-26. https://doi.org/10.1164/rccm.201703-0582OC

37. Kim HY, Kim JY, Park HY, Jun JH, Koo HY, Cho IY, et al. Health service utilization, unmet healthcare needs, and the potential of telemedicine services among Korean expatriates. Glob Health. 2018;14(1):120. https://doi. org/10.1186/s12992-018-0433-y.

38. Erwin J, Woolf A, Oyoo O, Cederlund I, Mwaniki L, Etau P. The UWEZO project-musculoskeletal health training in Kenya. Clin Rheumatol. 2016;35(2): 433-40. https://doi.org/10.1007/s10067-015-2863-8.

39. Chipeta JNP, McGill PE, Bucala R. Progress made towards enhancement of rheumatology education and practice in Zambia: review of an ILAR supported project. Clin Rheumatol. 2014;33:6.

40. Colmegna IBS, Oyoo OG. The ILAR East Africa initiative: current needs and progress in the globalization of rheumatology. Clin Rheumatol. 2011;30(2):3.

\section{Publisher's Note}

Springer Nature remains neutral with regard to jurisdictional claims in published maps and institutional affiliations. 